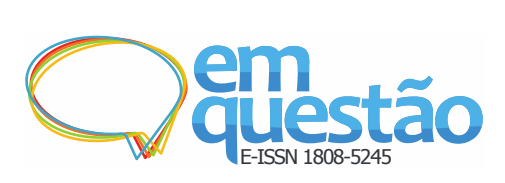

\title{
Diálogos entre as vertentes clássica, moderna e contemporânea da Arquivologia
}

\author{
Alex de Oliveira Costa \\ Mestre; Universidade de Brasília, Brasília, DF, Brasil; \\ alexbass2@gmail.com \\ Cynthia Roncaglio \\ Doutora; Universidade de Brasília, Brasília, DF, Brasil; \\ roncaglio@unb.br
}

\begin{abstract}
Resumo: O princípio da proveniência e os conceitos de documento de arquivo e organicidade que norteiam a Arquivologia desde o século XIX parecem, pelo menos parcialmente, não serem mais suficientes para explicar e orientar a produção dos documentos arquivísticos contemporâneos. Este artigo tem como objetivo analisar os argumentos e pressupostos das vertentes clássica, moderna e contemporânea da Arquivologia, que demonstram as particularidades e as contribuições de cada uma. A pesquisa caracteriza-se como qualitativa, de natureza exploratória, analítica e descritiva, na qual o método adotado é o levantamento bibliográfico. O referencial teórico baseou-se na história dos conceitos de Reinhart Koselleck e nos conceitos de ethos científico e discurso. Constatou-se no embate entre diferentes ideias e distintas abordagens, consideradas às vezes antagônicas, que é possível um diálogo entre elas mediante processos de ressignificação dos princípios e conceitos ao longo da própria dinâmica evolutiva da ciência.
\end{abstract}

Palavras-chave: Arquivologia. Documento de Arquivo. Princípio da Proveniência. Organicidade.

\section{Introdução}

Este artigo é um recorte de pesquisa de mestrado, a qual teve como objetivo analisar os argumentos e pressupostos apresentados pelas vertentes do pensamento arquivístico clássico, moderno e contemporâneo quanto ao princípio da proveniência e aos conceitos de arquivo e de organicidade que norteiam a Arquivologia desde o século XIX, a partir de estudos histórico-conceituais que demonstrem as particularidades dessas diferentes abordagens. A pesquisa caracteriza-se como qualitativa, de natureza exploratória, analítica e descritiva, na qual o método adotado é o levantamento bibliográfico. 


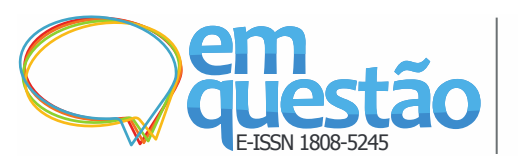

Diálogos entre as vertentes clássica, moderna e contemporânea da Arquivologia

Alex de Oliveira Costa e Cynthia Roncaglio

Devido às transformações tecnológicas, principalmente a partir da década de 1980, o debate teórico e prático a respeito de como a administração pública e privada registram e documentam suas ações e atividades ampliou-se. Tal debate parte do pressuposto que princípios e conceitos fundamentais da Arquivologia seriam de difícil aplicação ante as exigências da realidade digital e insuficientes para lidar com as ameaças que atingem os documentos contemporâneos. Esse debate desenvolveu-se principalmente no decorrer da transformação do objeto de trabalho dos arquivistas, o documento de arquivo, que passou a ser produzido digitalmente.

Apesar de identificarmos que as discussões se intensificaram a partir da década de 1980, consideramos necessário voltar nosso olhar ao final do século XIX, período no qual a Arquivologia despertou institucionalmente como área do conhecimento.

Cabe, porém, advertir que a divisão do processo histórico da Arquivologia varia entre os autores da área como, por exemplo, a apresentada por Fernanda Ribero (2011), que a divide em três fases: sincrética e custodial (séc. XVIII - 1898); técnica e custodial (1898 - 1980); e científica e póscustodial (1980 - atual). No entanto, por opção didática e metodológica, e tomando como base a tese de doutorado de Schmidt (2012), nosso recorte de pesquisa foi dividido em três períodos: clássico, moderno e contemporâneo. $\mathrm{O}$ período clássico engloba do final do século XIX até meados da década de 1940. O moderno compreende meados da década de 1940 até meados dos anos 1980. E, por fim, o contemporâneo abrange a década de 1980 em diante.

\section{História dos conceitos, ethos científico e discurso}

A abordagem historiográfica de Reinhart Koselleck (2006) desenvolveu-se a partir da definição sobre o que é tempo histórico. Para o autor, o tempo não é visto como algo natural e óbvio, mas é uma construção cultural que, em cada época, define uma maneira específica de relacionamento entre o já conhecido e experimentado no passado e as possibilidades que se apresentam ao futuro.

Koselleck (2006) afirma que, para toda análise de um conceito ou de um período histórico, existiria uma relação entre o espaço de experiências e o 


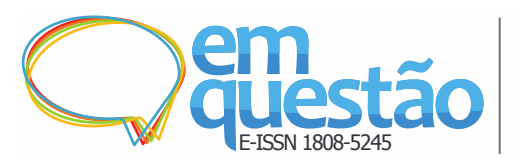

Diálogos entre as vertentes clássica, moderna e

horizonte de expectativas, propondo, assim, uma sistematização do tempo histórico. A história dos conceitos coloca em evidência a consolidação dos significados de um mesmo conceito em épocas diferentes.

Segundo Robert Merton (1970), a ciência deve ser regulada por ela própria, em sua autonomia, com base em uma ética peculiar, a do ethos científico. Conforme Trigueiro (2012, n. p.), a noção de ethos científico é bem conhecida na Sociologia da Ciência e significa “[...] conjunto de normas e regras de conduta que são seguidas pelos membros de uma comunidade científica [...]". Entretanto, as atividades científicas não envolvem apenas normas ou convenções, mas igualmente, o que alguns filósofos da ciência chamam de entidades. Estas significam "[...] constructos científicos, como os conceitos, as leis e as próprias teorias [...]" (TRIGUEIRO, 2012, n. p.). O que é característico das noções de entidades científicas é que decorrem de construções conceituais visando a cumprir determinado propósito no processo investigativo e a integrar uma teoria (TRIGUEIRO, 2012).

Sobre o conceito de discurso, Giddens e Sutton (2016), em uma definição prática, o definem como o "[...] modo de falar e pensar sobre um assunto, unido por princípios comuns. Seu intuito é estruturar a compreensão e as ações das pessoas sobre determinado assunto [...]" (GIDDENS; SUTTON, 2016, p. 7).

A partir da concepção de discurso de Giddens e Sutton (2016), seguimos para as propostas dos autores das vertentes clássica, moderna e contemporânea da Arquivologia, analisando os diferentes discursos em épocas e contextos específicos.

\section{Vertentes do pensamento clássico}

No século XIX e início do XX, a ciência obteve extraordinários avanços em todos os seus mais importantes ramos. Era comum, a organização institucional e acadêmica de pesquisa, onde o otimismo da época estava diretamente ligado à confiança na ciência e em seu poder de aperfeiçoar a situação do conhecimento.

A partir da necessidade de formular conceitos e princípios que pudessem conduzir as práticas arquivísticas existentes nas organizações, o 


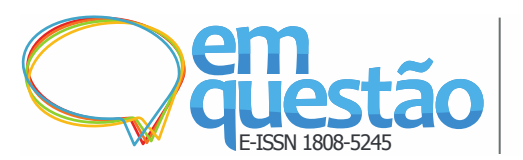

Diálogos entre as vertentes clássica, moderna e

desenvolvimento da Arquivologia no espaço científico apresentou algumas particularidades decorrentes dos diferentes rumos que a área tomou em cada país. Quatro manuais foram fundamentais para a consolidação da Arquivologia como área do saber: o da Associação dos Arquivistas Holandeses (1973); o de Hilary Jenkinson (1922); o manual de Eugenio Casanova (1928) e o de Adolf Brenneke (1968). Este período clássico foi marcado principalmente pela disseminação do princípio da proveniência e dos seus desdobramentos, do conceito de documento de arquivo e pela idealização da ideia de organicidade, a partir da publicação e divulgação de manuais que passariam a ser considerados clássicos para a Arquivologia.

O Handleiding voor het Ordenen en Beschrijven van Archieven, de Samuel Muller, Johan Feith e Robert Fruin, conhecido como manual dos arquivistas holandeses foi produzido pela Associação dos Arquivistas Holandeses em 1898. Traduzido para mais de 60 idiomas, sua tradução e publicação no Brasil foi apenas em 1960, realizada pelo Arquivo Nacional e intitulada Manual de Arranjo e Descrição de Arquivos.

Um dos pilares da teoria arquivística, o manual dos arquivistas holandeses é considerado um divisor de águas na história da Arquivologia como área do conhecimento. A partir dele, baseado em fundamentação teórica e princípios próprios, a Arquivologia busca tornar-se autônoma em relação à História e a outras áreas do conhecimento, como a Paleografia, a Diplomática e a Biblioteconomia.

Considerados pioneiros na divulgação dos princípios da proveniência e da ordem original, a Associação dos Arquivistas Holandeses (1973) entendeu que a proveniência é um princípio fundamental, que reflete sempre as funções do órgão, e que o arquivo é um todo orgânico, o qual não é criado arbitrariamente. Assim, identificamos no discurso dos autores a ênfase dada ao conceito de organicidade, onde as relações administrativas refletem-se nos conjuntos documentais, os quais espelham as funções e atividades da instituição, em suas relações internas e externas.

Sobre o conceito de arquivo, a Associação dos Arquivistas Holandeses (1973) o entende como: 


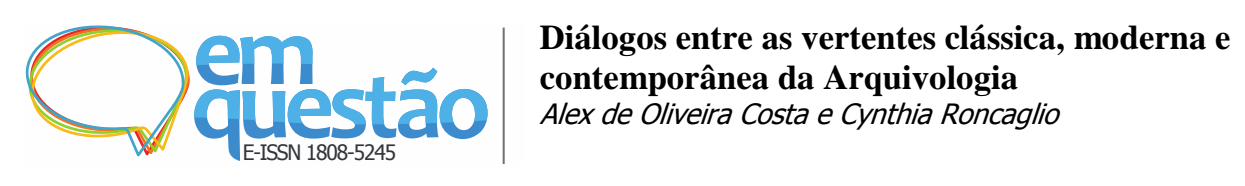

[...] conjunto de documentos escritos, desenhos e material impresso, recebidos ou produzidos oficialmente por determinado órgão administrativo ou por um de seus funcionários, na medida em que tais documentos se destinavam a permanecer na custódia desse órgão ou funcionário. (ASSOCIAÇÃO DOS ARQUIVISTAS HOLANDESES, 1973, p. 13).

Após a apresentação do conceito, os holandeses fazem alguns comentários para melhor explicá-lo. Os autores utilizaram, por exemplo, o termo conjunto para compreender arquivo como um conjunto de documentos. Levando-se em consideração a época na qual a obra foi publicada, o conceito apresenta os documentos escritos, desenhos e material impresso como as formas documentais possíveis para um documento de arquivo. Sobre a natureza dos documentos, fica nítida a supressão da referência às pessoas físicas no conceito. Entende-se, portanto, que os arquivos são decorrentes apenas de pessoas jurídicas.

Alguns anos depois, A Manual of Archive Administration Including the Problems of War Archives and Archive Making (1922), conhecido como Um Manual de Administração de Arquivo, de autoria do inglês Hilary Jenkinson, foi publicado em 1922, na Inglaterra, e reeditado em 1937 e 1965 . A obra retoma a proposta do manual dos arquivistas holandeses, destacando a visão administrativa dos arquivos e tornando-se um referencial para os arquivos britânicos.

O manual de Jenkinson (1922) surgiu como resposta à dificuldade de organização da massa documental acumulada na Inglaterra em virtude da Primeira Guerra Mundial. Suas experiências profissionais adquiridas no Public Record Office e suas habilidades no trato com os documentos medievais contribuíram sobremaneira para o propósito.

Ao mencionar a administração como um todo orgânico, Jenkinson (1922) definiu seu conceito de fundo como archive group. O autor reconheceu a aplicação da relação orgânica no estabelecimento da relação administrativa com a produção documental. 


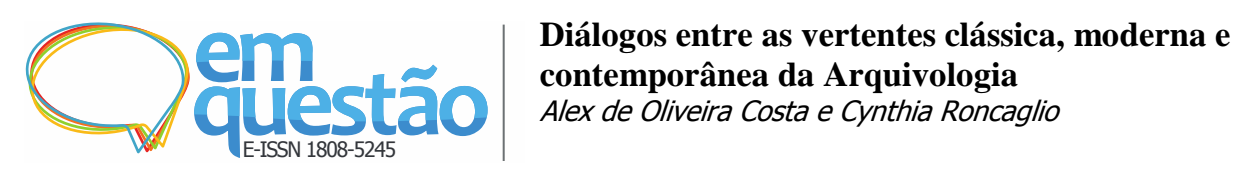

O fundo ou archive group é a principal unidade de arquivo no sistema continental e a base de todas as regras quanto ao arranjo. $\mathrm{O}$ mais importante de todos os princípios da Gestão de Arquivos, o respeito aos fundos, é nomeado a partir dele. (JENKINSON, 1922, p. 84 , tradução nossa). ${ }^{1}$

Ao definir o que compreende como arquivos, Jenkinson (1922) apresentou a questão da utilização dos termos records ou archives. Apesar de entender que ambos eram considerados como sinônimos, o autor reconheceu o uso de archives como mais adequado, devido a maior precisão do termo e ser habitualmente usado em outras línguas.

$\mathrm{O}$ autor abordou, ainda, o conceito de documento a partir de sua especificidade arquivística, elencando as formas como ele pode se apresentar. Para Jenkinson (1922),

Um documento dito como pertencente à classe dos arquivos é aquele que foi elaborado ou usado no decorrer de uma transação administrativa ou executiva (pública ou privada) da qual ele mesmo fazia parte; e, posteriormente, preservado em sua própria custódia e para sua própria informação pela pessoa ou responsáveis por essa transação e seus legítimos sucessores. (JENKINSON, 1922, p. 11, tradução nossa). ${ }^{2}$

Jenkinson (1922) conceituou documento arquivístico ao invés de arquivos. Ele apresentou o documento como um objeto individual, o qual pertence à classe dos arquivos. Ademais, assim como os holandeses, para ele a natureza dos arquivos refere-se apenas aos documentos produzidos ou recebidos por pessoas jurídicas. $\mathrm{O}$ autor também deu relevância à qualidade do caráter probatório de uma ação como característica indispensável ao documento de arquivo. Essa característica deve-se ao fato de os documentos não serem elaborados para interesse ou informação da posteridade, o que o diferencia do sentido frequentemente dado pelos historiadores (JENKINSON, 1922).

Outro ponto importante que deve ser destacado é a diferença entre os termos document (documento) e archives (arquivo) explorada pelo autor, o qual associa document ao uso corrente e archives aos documentos de guarda permanente.

Para Rondinelli (2013), 


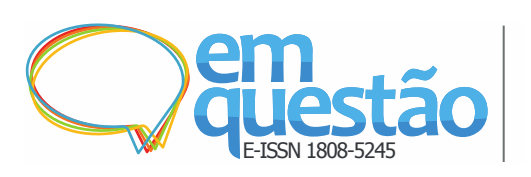

Diálogos entre as vertentes clássica, moderna e contemporânea da Arquivologia

Alex de Oliveira Costa e Cynthia Roncaglio

[...] parece que Jenkinson confunde um pouco o conceito de arquivo na medida em que favorece o entendimento de uma separação terminológica entre documento e arquivo pela qual este último só se aplicaria aos documentos de guarda permanente. (RONDINELLI, 2013, p. 154).

O modo de ver os documentos como uma consequência natural dose atos e transações de uma administração atribui as características de imparcialidade e autenticidade a partir da sua gênese. A imparcialidade deriva-se do fato que os documentos têm como objetivo precípuo atender à instituição que os produz. Enquanto que a autenticidade vem do fato que a custódia é exercida pela e para a instituição produtora ou seu legítimo sucessor, garantindo, assim, que os documentos não sofram alteração e mantenham uma cadeia ininterrupta de custódia. Caso a cadeia seja quebrada, os documentos não são confiáveis.

Mesmo depois de quase um século de existência, esse postulado de Jenkinson (1922), a cadeia ininterrupta de custódia, tem sido utilizado para a garantia de um documento confiável e autêntico para o século XXI.

Cabe ressaltar também a diferença estabelecida por Jenkinson (1922) entre verdade histórica e verdade arquivística. A primeira é caracterizada pelo conteúdo do documento, e a segunda está relacionada ao contexto de criação (SCHMIDT, 2012).

Poucos anos depois, na Europa, o manual Archivística (1928), de Eugenio Casanova, foi publicado em Siena, na Itália, a partir de suas experiências profissionais e com o intuito de facilitar sua didática durante as aulas.

O manual de Casanova (1928) consolidou a Arquivologia como disciplina científica na Itália, favorecendo sua autonomia em relação à História e à Diplomática, e foi o primeiro a denominar o termo Archivística. Nele, predominaram as abordagens teóricas e práticas dos arquivos e questões de organização e preservação dos documentos tiveram destaque. Casanova (1928) declarou que a Archivística é uma ciência porque tem os arquivos como objeto de estudo.

Quanto à proveniência, Casanova (1928) desenvolveu um olhar inovador para a aplicação desse princípio. Para o autor, a recuperação da informação efetua-se não observando apenas a ordem original, mas também a proveniência, 


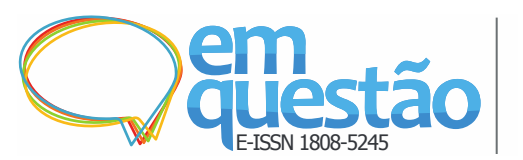

Diálogos entre as vertentes clássica, moderna e

a territorialidade e o contexto de criação e utilização dos documentos. O autor afirmou que o respeito aos fundos e à ordem original nem sempre se referem ao agrupamento físico dos documentos. Mesmo que os fundos estejam fisicamente separados e a ordem original tenha sido desfeita, a partir da descrição documental, pode-se reconstruir as relações orgânicas entre os documentos e a entidade produtora. Em vista disso, o respeito aos fundos e a ordem original podem ser recuperados intelectualmente, preservando, assim, a organicidade.

Cabe destacar que o autor italiano, assim como os holandeses, também enfatizava o conceito de organicidade. Porém, ao declarar que, por meio da descrição, o respeito aos fundos e à ordem original podem acontecer intelectualmente, inaugurava esse entendimento, o qual será adotado por vários autores a partir daquele momento.

Sobre o conceito de arquivo, Casanova (1928) o define como:

[...] reunião ordenada dos documentos de uma instituição ou indivíduo, constituídos durante o desenvolvimento de sua atividade e mantidos para consecução dos objetivos políticos, jurídicos e culturais daquela entidade ou indivíduo. (CASANOVA, 1928, p. 19, tradução nossa). ${ }^{3}$

Casanova (1928) considerava que essa definição era mais abrangente do que as apresentadas até aquele momento e, portanto, estaria adaptada aos arquivos públicos e privados. $\mathrm{O}$ autor também não fazia distinção entre o arquivo administrativo e o histórico, argumentando que o segundo deriva do primeiro.

Além de atribuir a natureza dos documentos também aos arquivos privados, Casanova (1928), assim como os holandeses, apresentou uma concepção de arquivo como uma reunião de documentos, só que evidenciando que é um acúmulo ordenado, constituído no decorrer das atividades (organicidade).

Na Alemanha, o manual de Adolf Brenneke, Archivkunde: ein Beitrag zur Theorie und Geschichte des Europäischen Archivwesens (Arquivos: contribuição para a teoria e a história dos arquivos europeus), foi publicado em 1953, sete anos após sua morte, em 1946, por seu aluno Wolfgang Leesch, que reuniu suas palestras e trabalhos em formato de manual. 


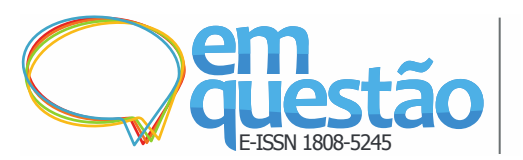

Diálogos entre as vertentes clássica, moderna e

A obra analisou o panorama dos arquivos alemães considerando a Arquivologia como uma ciência. O título de Brenneke (1968) destacou também outros pontos importantes, como proveniência, ordem original, organicidade e o conceito de arquivo.

Brenneke (1968) compreendeu o princípio da proveniência a partir da perspectiva funcional, não levando em consideração o atributo físico dos documentos. Ou seja, por meio da descrição, seria possível representar o contexto da produção documental, não sendo imprescindível o arranjo dos documentos físicos.

Portanto, observamos que o conceito de proveniência de Brenneke (1968) é similar ao de Casanova (1928). Brenneke (1968) também enfatizou a representação intelectual do contexto por meio da descrição, não considerando o agrupamento físico dos documentos como essencial para essa representação.

Analisando os conceitos de arquivo desenvolvidos por Heinrich August Erhard, pelo manual dos arquivistas holandeses e por Eugenio Casanova, Brenneke (1968) deduziu que quatro critérios foram utilizados por esses autores para definir a natureza dos arquivos: 1) a origem; 2) a limitação formal do conteúdo; 3) o aspecto organizacional; e 4) o propósito. A partir dessas características, que Brenneke (1968) considerou essenciais para o conceito, o autor apresentou sua definição de arquivo:

[...] conjunto de papéis e de outros documentos constituídos por pessoas físicas ou jurídicas no curso de sua atividade prática ou legal e que, como fontes documentais e provas do passado, se destinam à conservação permanente em um determinado local. (BRENNEKE, 1968, p. 125, tradução nossa). ${ }^{4}$

Da mesma maneira que o trio holandês e Casanova, Brenneke (1968) utilizou o termo conjunto referindo-se à acepção de arquivo como conjunto de documentos. Sobre as formas documentais, o autor diferenciou os papeis de outros documentos, ficando implícito que a caracterização de um documento como arquivístico independe do seu suporte, o qual pode ser produzido por pessoas físicas ou jurídicas no decorrer de sua atividade.

O autor, de maneira implícita, também desenvolveu a ideia de organicidade, ao declarar que os arquivos derivam do curso de suas atividades 


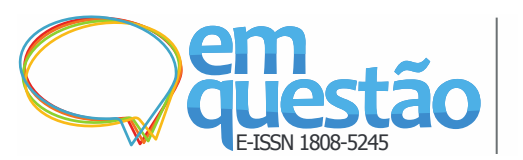

Diálogos entre as vertentes clássica, moderna e contemporânea da Arquivologia

Alex de Oliveira Costa e Cynthia Roncaglio

práticas e legais. Além disso, ao referir-se aos documentos arquivísticos como provas do passado, Brenneke atribuiu o caráter evidencial a esses.

Cabe destacar o fato de o autor realçar que os arquivos estão condicionados a uma guarda permanente em um local. Assim, podemos deduzir que os documentos que não são de guarda permanente não podem ser considerados como arquivo.

Observamos algumas semelhanças entre os autores da vertente clássica sobre os conceitos e princípios abordados. Todos eles enfatizam o conceito de organicidade. Porém, Brenneke (1968), ao enfatizar a representação intelectual do contexto por meio da descrição, não considerando o agrupamento dos documentos como essencial para essa representação, se aproxima de Casanova (1928), o qual também declara que, por meio da descrição, o respeito aos fundos e à ordem original poderiam acontecer apenas intelectualmente.

\section{Vertentes do pensamento moderno}

Após a Segunda Guerra Mundial, manifesta-se um grande aumento na produção documental das instituições públicas e privadas. O documento de arquivo, objeto de estudo dos arquivistas, tem o seu alcance ampliado para uma dimensão administrativa, focado no viés da gestão.

Também nesse período, diferenças terminológicas são reveladas dentro da comunidade científica arquivística, novos princípios são elaborados ou os antigos são adaptados para as novas realidades. Surgem periódicos, associações profissionais e organismos internacionais, como o International Council on Archives [Conselho Internacional de Arquivos].

Como consequência da preocupação de reduzir a massa documental acumulada e zelar pelos documentos produzidos e recebidos pelo governo norteamericano, surge, em 1934, a fundação do National Archives of the United States [Arquivo Nacional dos Estados Unidos]. Theodore Roosevelt Schellenberg, recém-formado em História, foi convidado em 1935 para assumir um cargo no respectivo arquivo, onde permaneceu até 1956. Além disso, em 1954, a partir de um convite feito pela National Librarian Harold White, Schellenberg permaneceu na Austrália, na cidade de Canberra, por volta de seis 


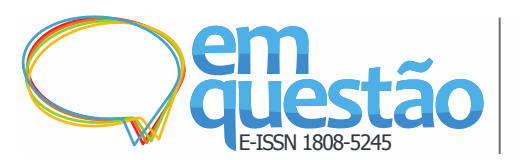

Diálogos entre as vertentes clássica, moderna e contemporânea da Arquivologia

Alex de Oliveira Costa e Cynthia Roncaglio

meses e meio, onde apresentou uma série de palestras para os bibliotecários australianos que buscavam orientação sobre a administração de arquivos. Produto desse cenário, onde trabalhou por mais de 20 anos, e como extensão de suas conferências na Austrália, surgiu, então, sua obra mais conhecida, Modern Archives, principles \& techniques, publicada em 1956, nos Estados Unidos, e traduzida para o português em 1973, por Nilza Teixeira, com o título Arquivos Modernos, princípios e técnicas.

A partir da ideia das relações orgânicas naturais dos arquivos, Schellenberg (1956) interpretou o princípio da proveniência como o fundamento da teoria e práticas arquivísticas. O autor também incluiu o respeito aos fundos e a ordem original no contexto da proveniência, principalmente quando se referiu aos arquivos históricos.

Diante da grande produção documental e da dificuldade crescente de tratar os documentos, criticando a ideia de archive group de Hilary Jenkinson, Schellenberg determina o record group como metodologia para organizar os archives [documentos de guarda permanente]. As unidades administrativas classificariam os records [documentos correntes] a partir das divisões internas dos documentos de uma mesma proveniência, os records groups. Assim, os archives seguiriam a mesma classificação que os records.

Sobre as características de um documento de arquivo, Schellenberg (1956) destacou, a partir das definições dadas por arquivistas dos diversos países até aquele momento, os elementos tangíveis e intangíveis. Para o autor, os tangíveis - a forma dos arquivos, a fonte de origem e o lugar de sua conservação - não seriam os elementos essenciais para a caracterização do material de arquivo, e sim os intangíveis. Schellenberg aponta apenas dois elementos intangíveis (SCHELLENBERG, 2005).

$\mathrm{O}$ primeiro refere-se à razão pela qual os materiais foram produzidos e acumulados. "Para serem considerados arquivos, os documentos devem ter sido criados e acumulados na consecução de algum objetivo [...]" (SCHELLENBERG, 2005, p. 37). Para Schellenberg (2005), a razão pela qual os documentos vieram a existir é importante. 


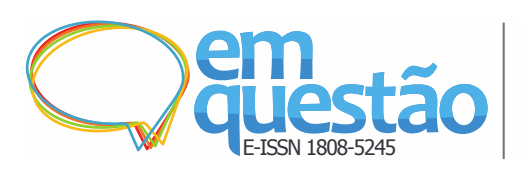

Diálogos entre as vertentes clássica, moderna e contemporânea da Arquivologia

Alex de Oliveira Costa e Cynthia Roncaglio

[...] Se foram produzidos no curso de uma atividade organizada, com uma determinada finalidade, se foram criados durante $o$ processo de consecução de um certo fim administrativo, legal, de negócio ou qualquer outro fim social são então considerados como tendo qualidade de material de arquivo em potencial. (SCHELLENBERG, 2005, p. 38).

O segundo refere-se aos valores pelos quais os arquivos são preservados. "Para que os documentos sejam arquivados devem ser preservados por razões outras que não apenas aquelas para as quais foram criados ou acumulados. Essas razões tanto podem ser oficiais quanto culturais [...]" (SCHELLENBERG, 2005, p. 38).

Em oposição a Jenkinson (1922), o qual considerava que os documentos se tornariam arquivos apenas se a custódia ininterrupta fosse estabelecida, ou, se ao menos fosse possível estabelecer uma presunção razoável da mesma, Schellenberg (2005) argumentava que, para os documentos modernos do governo, esse critério não poderia ser levado em conta para incluir documentos (records) na categoria arquivos. Para o autor, os documentos modernos existiam em grande volume, eram de origem complexa e sua criação era, muitas vezes, casual. Schellenberg entendeu que a maneira pela qual os documentos modernos eram produzidos tornou "[...] infrutífera qualquer tentativa de controlar os documentos de per si, isto é, isoladamente, ou, em outras palavras, de seguir 'linhas imaculadas' de 'custódia intacta [...]”' (SCHELLENBERG, 2005, p. 39).

$\mathrm{O}$ autor norte-americano enfatizou que o arquivista moderno deveria se interessar pela qualidade dos documentos que recebe, aspirando a ter a integridade dos documentos preservados. Para isso, os documentos de um determinado órgão

[...] a) devem ser conservados num todo como documentos desse órgão; b) devem ser guardados, tanto quanto possível, sob o arranjo que lhes foi dado pelo órgão no curso de suas atividades oficiais; e c) devem ser guardados na sua totalidade, sem mutilação, modificação ou destruição não autorizada de uma parte deles [...] (SCHELLENBERG, 2005, p. 39-40).

Porém, aqui, podemos nos questionar: seria suficiente que os documentos de guarda permanente fossem preservados em sua totalidade, sem mutilação ou destruição não autorizada, mesmo se houvesse a ausência da 


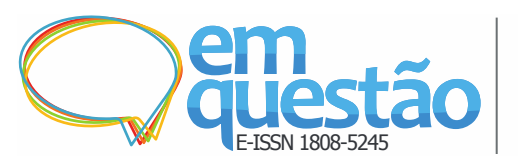

Diálogos entre as vertentes clássica, moderna e contemporânea da Arquivologia

Alex de Oliveira Costa e Cynthia Roncaglio

custódia ininterrupta? Entendemos que esse pensamento de Schellenberg seria uma forma de chamar atenção para o infortúnio causado pelas grandes massas documentais produzidas naquele período, onde haveria a possibilidade de os acervos não constarem em sua totalidade.

Sobre a definição do conceito de arquivo, diferentemente de Jenkinson (1922), Schellenberg (1956) formulou sua definição a partir de dois termos distintos: records e archives.

Para o autor, records compreendia

Todos os livros, papéis, mapas, fotografias ou outras espécies documentárias, independentemente de sua apresentação física ou características, expedidos ou recebidos por qualquer entidade pública ou privada no exercício de seus encargos legais ou em função das suas atividades e preservados ou depositados para preservação por aquela entidade ou por seus legítimos sucessores como prova de suas funções, sua política, decisões, métodos, operações ou outras atividades, ou em virtude do valor informativo dos dados neles contidos. (SCHELLENBERG, 2005, p. 41).

Quanto aos archives, Schellenberg definiu como:

Os documentos de qualquer instituição pública ou privada que hajam sido considerados de valor, merecendo preservação permanente para fins de referência e de pesquisa e que hajam sido depositados ou selecionados para depósito, num arquivo de custódia permanente. (SCHELLENBERG, 2005, p. 41).

Schellenberg fez, então, uma diferenciação entre as razões pelas quais os documentos vieram a existir para evidência e informação (records) - mantidos pelo produtor - e razões pelas quais foram preservados para referência e pesquisa (archives) - mantidos por uma instituição arquivística. Os records estariam vinculados às fases corrente e intermediária, enquanto que os archives se referiam à fase permanente.

A partir de sua obra Modern Archives, principles \& techniques (1956), Schellenberg passou também a ser considerado como o pioneiro da avaliação arquivística. Para resolver o problema do crescimento da produção documental, preservando apenas os documentos considerados importantes e históricos, o autor associa o documento arquivístico aos valores que ele obtém ao longo do 


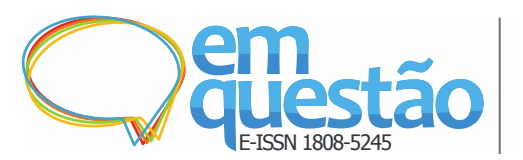

Diálogos entre as vertentes clássica, moderna e

ciclo de vida. Sendo assim, explicou seu conceito no qual os documentos possuem dois valores: o primário e o secundário.

O valor primário é para o uso da própria entidade onde se originaram os documentos. Conforme salientou Schellenberg (2015, p. 180-181), “[...] os documentos nascem do cumprimento dos objetivos para os quais um órgão foi criado - administrativos, fiscais, legais e executivos [...]”. O valor secundário é para o uso das outras entidades e utilizadores privados, dividido em valor probatório - a prova que contêm da organização e do funcionamento do órgão governamental - e valor informativo - a informação que contêm sobre pessoas, entidades, coisas, problemas, condições etc. com que o órgão governamental haja tratado.

Em discordância com Schellenberg, surge a figura do jovem linguista Peter Scott, recém-nomeado em 1964 para trabalhar no arquivo de Commonwealth na Austrália, que fez uma sugestão radical: abandonar a abordagem do record group e adotar o que nomeou de series system, ou sistema de séries. A partir desse sistema, “[...] seria possível descrever as relações entre os documentos, os criadores e os processos que o demandaram de maneira a abarcar todo o seu trâmite independente das instabilidades administrativas [...]" (SCHMIDT, 2012, p. 161).

Para Scott (1966), a aplicação do series system consolidaria os relacionamentos entre os documentos e seu contexto de produção. Em uma versão simplificada, o autor apresentou seu sistema a partir de dois componentes básicos: o controle do documento e o controle do contexto.

Pelo fato de os documentos possuírem simultâneas e sucessivas relações de proveniência, nas quais essas deveriam estar inter-relacionadas, Scott (1966) buscava encontrar maneiras mais eficientes de documentar esses complexos sistemas de proveniência, já que a abordagem do record group não era mais considerada como eficaz para esse tipo de situação. Schmidt (2012) entende a proposta de Scott (1966) como

[...] um modelo que respeita o Princípio da Proveniência e, diferentemente dos americanos que trabalham com subgrupos baseados na estrutura administrativa, partem das Séries de documentos criadas pelas funções para então classificá-los. (SCHMIDT, 2012, p. 162). 


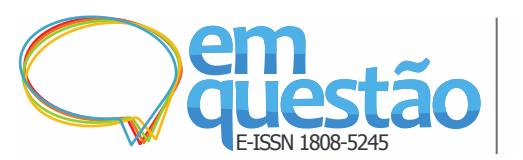

Diálogos entre as vertentes clássica, moderna e

Sendo assim, Scott pretendia ter o controle intelectual dos documentos por meio da descrição dos vários contextos, os quais reproduziriam a natureza dinâmica de criação daqueles. Ademais, pelo fato de o contexto administrativo estar registrado em instrumentos de descrição, essa nova sistemática possibilitaria a não inclusão das séries em uma ordem física original.

Observamos que a abordagem do sistema de séries de Scott (1966) se aproxima das concepções de Casanova (1928) e Brenneke (1968). Conforme exposto anteriormente, Casanova (1928), ao refletir sobre a aplicação do princípio da proveniência, destacou que a recuperação da informação deve considerar a observação do contexto de criação e utilização dos documentos, e que, mesmo que os fundos estejam fisicamente separados e a ordem original tenha sido desfeita, os documentos, a partir da organização intelectual e da descrição, poderão manter suas relações orgânicas com a entidade produtora. Assim também entendia Brenneke (1968), o qual não levava em consideração o agrupamento físico dos documentos. Para o autor, por meio da descrição, seria possível representar o contexto da produção documental, não sendo imprescindível o arranjo físico dos documentos.

\section{Vertentes do pensamento contemporâneo}

Imersa num contexto digital de complexidades e imprecisões, a comunidade científica arquivística deparou, sobretudo a partir dos anos 1990, com um novo problema: o documento de arquivo, objeto de trabalho dos arquivistas, passou a ser produzido em sistemas informatizados, onde conteúdo e suporte estão dissociados, dificultando a identificação da proveniência e o interrelacionamento entre os documentos. Além disso, sob o advento da chamada era da informação ou sociedade da informação, e das reconfigurações políticoinstitucionais das universidades em vários países, algumas abordagens passaram a compreender a Arquivologia como uma área subordinada à Ciência da Informação, interpretando que o objeto de estudo deixou de ser o documento de arquivo e passou a ser a informação.

Concebido na Austrália, em 1996, por Frank Upward, o modelo records continuum desenvolveu-se a partir da dificuldade de implementar a gestão dos 


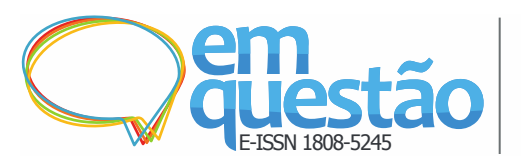

Diálogos entre as vertentes clássica, moderna e

documentos arquivísticos digitais. Segundo tal modelo, demonstrando sua natureza sincrônica ao invés de linear, a produção, o uso e a preservação dos documentos considerados em três fases distintas, apregoadas pelos defensores do conceito de ciclo de vida dos documentos, mostraram-se insuficientes para garantir a integridade e contextualização dos documentos que são gerados simultaneamente e, às vezes, por diversos produtores em contextos contínuos de inter-relação. Upward (1996, p. 1) considerou o modelo records continuum como “[...] resultado de uma mistura teórica entre Arquivologia, PósModernismo e Teoria de Estruturação de Anthony Giddens [...]”.

Em sua obra Structuring the Records Continuum - Part One: Postcustodial Principles and Properties (1996), Upward demonstrou as propriedades do records continuиm por meio de um modelo constituído de eixos, coordenadas e dimensões, destacando que o modelo é contínuo e que se trata de um construto espaço-temporal, diferentemente da abordagem do ciclo de vida.

Sobre o conceito de documento arquivístico, Sue Mckemmish e Frank Upward, em seu artigo The Archival Document, consideraram que:

[...] o documento arquivístico pode ser melhor conceituado como informação registrada resultante de transações - ele é criado naturalmente no curso de transações de qualquer tipo, seja por governos, empresas, organizações comunitárias ou indivíduos particulares. (MCKEMMISH; UPWARD, 19915, apud MCKEMMISH et al., 2005, n. p., tradução nossa). ${ }^{6}$

Os autores, ao se referirem ao documento arquivístico, não utilizaram o termo record, e sim archival document. Destacaram, também, que a documentação de uma transação é arquivística "[...] a partir do momento em que o documento é criado e o documento arquivístico retém o valor evidencial durante o tempo em que existe [...]" (MCKEMMISH; UPWARD, 1991, apud MCKEMMISH et al., 2005, n. p., tradução nossa). ${ }^{7}$

Como dito anteriormente, a partir do que considera como princípios estruturais para sua teoria do continuum, Upward (1996), ao conceituar o documento arquivístico contínuo, enfatizou seu uso para propósitos transacionais, comprobatórios e de memória, unificando abordagens para arquivamento e manutenção de documentos, mesmo se os documentos fossem 


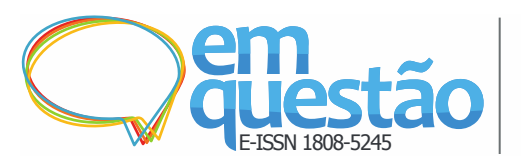

Diálogos entre as vertentes clássica, moderna e

mantidos por uma fração de segundo ou um milênio. $\mathrm{O}$ autor entende os documentos como entidades lógicas ao invés de físicas, independentemente de serem produzidos em suporte papel ou eletrônico, destacando-os como uma representação intelectual. Os documentos arquivísticos são vistos como evidência de transações contextualizadas no tempo e no espaço, de maneira dinâmica.

Para Mckemmish (2005, n. p.), os documentos arquivísticos são fixos e mutáveis ao mesmo tempo, "sempre em processo de transformação". Essa visão contrasta com as ideias tradicionais de documento, que enfatizam a natureza fixa e estática, totalmente formado e fechado. Para a autora, os documentos arquivísticos estão ligados a outros e camadas cada vez mais amplas de metadados contextuais gerenciam seus significados e permitem sua acessibilidade e usabilidade à medida que se movem pelo espaço-tempo.

Em síntese, o modelo records continuum apresenta o conceito de documento arquivístico contínuo a partir da unificação dos termos records e archives; dá ênfase à natureza evidencial, transacional e contextual dos documentos; e proporciona uma visão multidimensional da produção dos documentos no contexto social e organizacional, ligando-os a camadas de metadados contextuais.

Conduzindo esta dialética para o Canadá, a Arquivística Integrada, escola canadense francesa, surgiu ainda na década de 1980 representada principalmente pelos canadenses Carol Couture e Jean Yves Rousseau.

Resultante da era da informação, a Arquivística Integrada traz uma perspectiva de uma Arquivologia nova, integradora e englobante, inserida no campo da Ciência da Informação. Seu foco é a gestão da informação orgânica, a qual vai além da gestão documental, onde terá um papel determinante para a disseminação das informações e tomada de decisão nas organizações.

Desempenhando sua função com o foco na gestão da informação, essa nova Arquivística pretende integrar todas as fases do ciclo de vida dos documentos, desde os documentos correntes até os permanentes, garantindo uma unidade em todo o trabalho arquivístico, onde a classificação poderá ocorrer em qualquer etapa dessa vida dos documentos. 


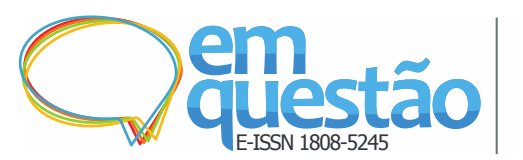

Diálogos entre as vertentes clássica, moderna e

Cabe destacar que essa pretensão de garantir uma unidade em todo o trabalho arquivístico e integrar todas as fases do ciclo vital dos documentos é diferente da abordagem do modelo australiano records continuum. A Arquivística Integrada respeita a perspectiva das três fases/idades documentais, sugerindo a integração dessas. O modelo records continuum possui uma natureza sincrônica ao invés de linear, não contendo a divisão de fases/idades.

Rousseau e Couture (1998, p. 79) acreditam que o princípio da proveniência é a base teórica da Arquivologia, “[...] a lei que rege todas as intervenções arquivísticas [...]”. Para os autores, todas as intervenções do arquivista devem ocorrer sob o princípio da proveniência e do reconhecimento do fundo como unidade central das operações arquivísticas. Consideram também que a proveniência se desdobra em dois graus: $1^{\circ}$ ) respeito aos fundos, e $\left.2^{\circ}\right)$ respeito à ordem original.

A partir desse contexto, surgem os conceitos de informação orgânica e informação não orgânica. A orgânica é “[...] aquela que é elaborada, enviada ou recebida no âmbito da missão da organização [...]”. A não orgânica é “[...] produzida fora do âmbito da missão da organização e existe muitas vezes nos locais de trabalho, na biblioteca ou no centro de documentação [...]" (ROUSSEAU; COUTURE, 1998, p. 64-65).

Os autores também afirmam que "[...] a produção de informações orgânicas registradas dá origem aos arquivos [...]" (ROUSSEAU; COUTURE, 1998, p. 65). Portanto, interpretamos que Rousseau e Couture (1998) consideram informação orgânica como sinônimo de documento de arquivo. Por não considerar a distinção entre records e archives, essa informação orgânica pode ter um valor primário e secundário.

Ainda no Canadá, destaca-se também a Arquivística Funcional ou PósModerna, que é uma abordagem da escola canadense inglesa que surgiu no final da década de 1980. Iniciada por Hugh Taylor, foi aperfeiçoada e aprofundada mediante os estudos do canadense Terry Cook, crítico das ideias das vertentes clássica e moderna.

O nome Arquivística Funcional surgiu de uma abordagem Pós-Moderna que se baseia na análise funcional do processo de produção dos documentos. $\mathrm{O}$ 


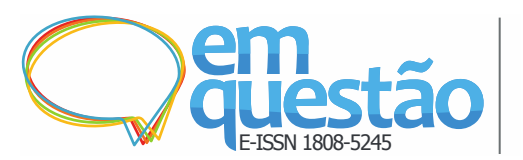

Diálogos entre as vertentes clássica, moderna e

principal foco dessa abordagem é compreender o contexto por trás do texto. $\mathrm{O}$ importante é analisar quem, por que e como produziu, além de saber quais as intenções por trás do texto produzido. Diferentemente da Diplomática Arquivística/Contemporânea, que veremos adiante, essa análise parte no sentido do criador para o documento, e não o contrário, permitindo uma melhor compreensão da função, do processo e das atividades que o geraram.

Observamos que o que parece ser uma abordagem inovadora, em parte reproduz pressupostos já contemplados desde a vertente clássica. Essa perspectiva funcional que destaca a recuperação intelectual da informação por meio da observação do contexto de criação e utilização dos documentos, sem se preocupar com o agrupamento físico dos documentos, vem sendo desenvolvida desde autores como Casanova (1928) e Brenneke (1968).

Cook (1997) considera o princípio da proveniência como fundamental para a teoria e práticas arquivísticas. Porém, ele o amplia e o (re)define a partir da ideia do contexto por trás do texto. A proveniência torna-se mais conceitual do que física, o que seria apropriado para a era do documento digital. A nova proveniência também é mais funcional que estrutural, uma vez que é apropriada para uma época onde a estabilidade organizacional está desaparecendo em todos os lugares. A proveniência refletirá as funções e atividades que levaram o produtor a criar um documento, seja em uma instituição ou em uma organização dinâmica, com pessoas diferentes em diversas localidades. Ou seja, a proveniência é virtual e se relaciona à função e atividade geradora. $\mathrm{O}$ foco passa para as propriedades dos documentos como testemunho de ações e transações do seu criador no contexto orgânico de sua produção e manutenção dos documentos, para que se analise e avalie o porquê da criação dos documentos (COOK, 1997, p. 31-32).

Por refletir essa nova abordagem de proveniência, a aplicação do princípio da ordem original não é mais possível ou não faz mais sentido. A classificação e a descrição dos documentos devem ser aplicadas não mais às entidades físicas documentais, e sim à compreensão contextual das relações do documento com seu contexto de criação. 


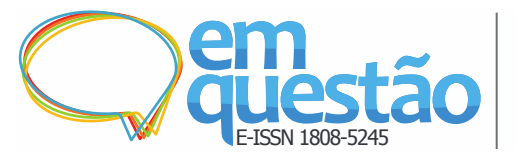

Diálogos entre as vertentes clássica, moderna e

Para Cook, o documento arquivístico não deve ser compreendido como um objeto estático e físico, mas como um conceito dinâmico e virtual, não mais um subproduto passivo, mas um agente ativo na memória coletiva e organizacional. Segundo Cook (2007)

Nesse ambiente eletrônico fluido, a ideia de um documento pertencente fisicamente a um lugar ou mesmo a um sistema está desmoronando diante de novos paradigmas conceituais, em que o "criador" é um processo mais fluido de manipular informações de várias fontes e de várias maneiras, ao invés de algo que leva a um produto físico estático e fixo. (COOK, 2007, p. 423, tradução nossa). ${ }^{8}$

Ademais, o autor compreende que os três componentes de um documento arquivístico - conteúdo, estrutura e contexto -, que eram tradicionalmente fixados em um meio físico, agora são separados em diferentes bases de dados e em diferentes programas de software. Assim,

[...] o documento deixa de ser um objeto físico para se tornar um "objeto" de dados conceituais, controlado por metadados que virtualmente combinam conteúdo, contexto e estrutura, para fornecer evidências de alguma atividade ou função do criador. Além disso, como o contexto e as alterações de uso do documento mudam ao longo do tempo (incluindo o uso arquivístico), os metadados são alterados, e o documento e seu contexto são continuamente renovados. Os documentos não são mais fixos, são dinâmicos. (COOK, 2000, n. p., tradução nossa). ${ }^{9}$

Uma das mais importantes contribuições de Terry Cook para a Arquivologia foi o conceito macroappraisal, ou macroavaliação. Desenvolvido pelo autor no final da década de 1980, foi formalmente adotado e lançado pelo governo federal canadense na primavera de 1991 (COOK, 2005).

Intitulado pelo próprio autor como a maneira canadense de se fazer uma avaliação arquivística, sua proposta critica veementemente as ideias de avaliação apresentadas por Schellenberg (1956). Cook (2005) resume seu conceito da seguinte forma:

[...] a macroavaliação avalia o valor social do contexto funcionalestrutural e da cultura do local de trabalho no qual os documentos são criados e utilizados por seus criadores, e a inter-relação dos cidadãos, grupos, organizações - "o público" - com aquele contexto 


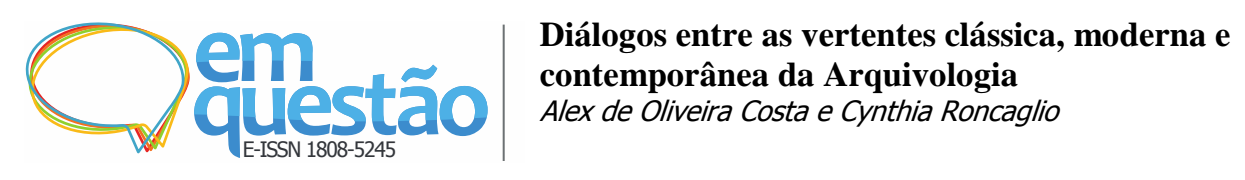

funcional-estrutural. Se a avaliação designa o valor a longo prazo do conteúdo dos documentos, ou séries documentais, para seus potenciais valores de pesquisa, a macroavaliação avalia o significado do seu contexto de criação e uso contemporâneo. A avaliação é sobre documentos; a macroavaliação é sobre seu contexto mais amplo (ou "macro"). (COOK, 2005, p. 101-102, tradução nossa). ${ }^{10}$

Assim, segundo Cook, a macroavaliação é a avaliação das funções e atividades dos criadores dos documentos, não mais baseada no valor potencial de pesquisa, considerando o contexto mais importante do que o conteúdo do documento e refletindo como os cidadãos interagem com esse contexto.

Por entender que existem muitos contextos por trás dos textos, o pressuposto da macroavaliação é que o significado do documento é relativo e cabe ao arquivista moldar o sentido do documento, ao permitir que outras histórias sejam contadas, além da explícita no documento, através da história dos seus criadores e do porquê de sua criação. Ou seja, ao estabelecer as políticas de avaliação, selecionando os documentos que deverão ser preservados, o arquivista está decidindo o que deve ser lembrado ou esquecido pela sociedade. Segundo Cook, “[...] nós, arquivistas, [...] estamos literalmente coproduzindo os arquivos. Nós estamos fazendo história. Estamos exercendo o poder sobre a memória [....]" (COOK, 2005, p. 103, tradução nossa). ${ }^{11}$

Por fim, Terry Cook (2007) entende que, se os arquivistas se reorientarem do conteúdo para o contexto, ou seja, do documento para os processos criadores por trás dele e, portanto, para as ações, programas e funções por trás desses processos,

[...] servirão melhor aos seus usuários e "patrocinadores", pois identificarão, preservarão, descreverão e disponibilizarão para aqueles não meros fatos e dados, mas toda a riqueza revelada nos documentos como evidências de transações contextualizadas. (COOK, 2007, p. 410).

Essa visão de Cook, sobre o trabalho a ser feito pelos arquivistas, parece uma tarefa hercúlea posto que, além de pesquisar e cuidar de todos os processos de criação, manutenção, uso e recuperação contextual dos documentos, deverão ainda investigar e contextualizar também ações, programas e funções relacionados a esses documentos, o que os aproximaria mais da missão de um 


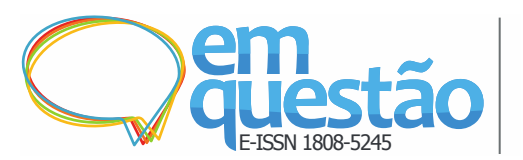

Diálogos entre as vertentes clássica, moderna e

historiador do que propriamente de um arquivista. Ademais, ainda que se considerando o mérito das suas reflexões, sua obra não menciona ou discorre sobre uma metodologia para realizar essa proposta de avaliação.

Também a partir dos pensamentos de Hugh Taylor, Theo Thomassen, assim como Terry Cook, compartilha a ideia que a Arquivologia está vivendo uma mudança de paradigma. Thomassen (1999) se apoia nas teorias de Thomas Kuhn para fundamentar seu pensamento.

O conceito de paradigma foi apresentado por Thomas Kuhn em sua obra The Structure of Scientific Revolutions. Para Kuhn (1962), paradigma é uma conquista científica universalmente reconhecida que, por algum tempo, modela problemas e soluções para uma comunidade de cientistas praticantes. Um paradigma também fornece o modelo explicativo de uma disciplina científica no estágio específico de seu desenvolvimento e define seus fundamentos. Não seria um processo linear de acumulação de conhecimento, mas um processo no qual a ciência normal e as revoluções científicas se alternam, um processo em que diferentes estágios podem ser distinguidos: pré-paradigmático, revolução científica, ciência normal, nova revolução científica.

Theo Thomassen (1999) faz uma análise sobre essa mudança de paradigma a partir do que ele considera como os componentes fundamentais da Arquivologia: seu objeto, suas entidades fundamentais e suas interações, seus objetivos, seus métodos e suas técnicas.

Para Thomassen (1999), a Arquivologia clássica seria aquela que foi representada emblematicamente pelo Manual de Arranjo e Descrição de Arquivos (1898), conhecido como manual dos arquivistas holandeses, já apresentado aqui. $\mathrm{O}$ autor identifica como sendo o seu objeto de estudo o conjunto de documentos criados ou recebidos por uma administração ou um funcionário público. Identifica também o item físico como a entidade fundamental. As interações entre essas entidades, item físico ou item documental, seriam consideradas orgânicas por natureza. Seguindo seu raciocínio, Thomassen esclarece que o objetivo da ciência Arquivística Clássica seria o controle físico e intelectual dos documentos. Já em relação à metodologia, consistiria na aplicação do princípio da proveniência e da ordem 


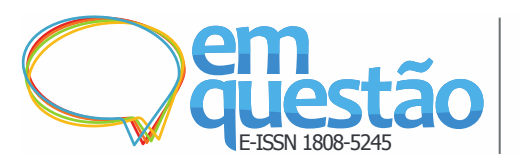

Diálogos entre as vertentes clássica, moderna e contemporânea da Arquivologia

Alex de Oliveira Costa e Cynthia Roncaglio

original. E, por fim, a técnica era caracterizada pela descrição formal dos documentos físicos e seu arranjo de acordo com uma classificação natural, que espelharia a organização do criador dos documentos.

Caracterizando o novo paradigma da Arquivística, o Pós-Custodial, Thomassen (1999, n. p.) acredita que, apesar de considerar uma tarefa muito difícil, os arquivistas deveriam estar preparados para correr o risco de estabelecer os novos fundamentos desse paradigma. O que o autor chama de novo objeto é process-bound information (informação vinculada ao processo), ou seja: informação gerada e estruturada pelos processos de negócios, a fim de possibilitar, como ponto de partida, a recuperação contextual. É um objeto duplo, porque se refere à informação arquivística e ao seu contexto gerador, que são os processos de criação dos documentos. Seguindo nessa linha, o autor também considera a entidade fundamental como dupla: é o documento lógico individual em sua relação com a transação de negócio geradora.

Apesar de utilizar a expressão process-bound information (informação vinculada ao processo) para definir o novo objeto da Arquivologia, não conseguimos perceber a diferença em relação ao antigo objeto. Interpretamos que, assim como Rousseau e Couture (1998), que consideram informação orgânica como sinônimo de documento de arquivo, Thomassen deveria perceber que essa informação, que é vinculada aos processos de negócios, se manifesta justamente por meio dos documentos de arquivo. Ademais, sobre o contexto gerador, novamente observamos que, o que ele diz ser uma abordagem inovadora, nada mais é que a reprodução de ideias já difundidas desde a vertente clássica. Reiteramos que a recuperação intelectual da informação por meio do contexto gerador, e que não se baseia exclusivamente no agrupamento físico dos documentos, vem sendo desenvolvida desde autores como Casanova (1928) e Brenneke (1968).

Ademais, para Thomassen (1999), o objetivo desse novo paradigma é muito mais que garantir a acessibilidade, é o que o autor chama de qualidade arquivística: a transparência, a força e a estabilidade duradoura do vínculo entre a informação e os processos de negócios geradores. A metodologia consiste no estabelecimento, na manutenção e na análise dos vínculos entre os documentos e 


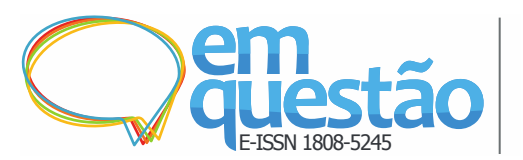

Diálogos entre as vertentes clássica, moderna e

seus criadores, a fim de estabelecer, manter e analisar a autenticidade, confiabilidade e fidedignidade dos documentos. Por fim, as técnicas características são a aplicação de técnicas de modelagem e padrões descritivos.

Mais uma vez podemos questionar: esse vínculo entre a informação e os processos de negócios geradores não seria exatamente a organicidade, a qual desde os autores da vertente clássica já faz parte, implícita ou explicitamente, dos princípios e conceitos da Arquivologia?

Por fim, baseado nessas ideias inovadoras e motivado pela revolução tecnológica, Thomassen (1999) considera que o novo paradigma da Arquivologia é muito mais do que uma mudança do suporte papel para o suporte digital; é uma mudança do clássico ou moderno para o que ele chamaria de póscustódia ou, como sugeriu Terry Cook, o paradigma Pós-Moderno da Arquivologia.

Também no Canadá, Luciana Duranti passou a sugerir que a Diplomática passa por um processo de reinvenção, apoiada em suas bases teóricas e metodológicas construídas desde o século XVII. A partir da inquietação com o desafio do documento arquivístico em seu novo ambiente eletrônico, a nova Diplomática Arquivística/Contemporânea deriva desse processo de reinvenção com o foco nos documentos arquivísticos contemporâneos.

Segundo Duranti (2009), a Diplomática Arquivística/Contemporânea não representa uma evolução da Diplomática, mas a autora considera que as duas coexistem em paralelo e possuem diferentes objetos de estudo. A Diplomática Arquivística/Contemporânea “[...] adaptou, elaborou e desenvolveu os conceitos centrais e a metodologia da Diplomática Clássica para estudar documentos modernos e contemporâneos de todos os tipos [...]" (DURANTI, 2009, p. 2, tradução nossa). ${ }^{12}$

Assim, para que o arquivista pudesse compreender os conjuntos documentais, Duranti propõe um método chamado tipologia documental. Segundo Tognoli (2010),

[...] por meio da análise tipológica, o arquivista pode identificar a função do documento e seu contexto de produção, focando sua análise na evidência, a partir de seus elementos formais, independentemente de outras fontes alternativas, como os 


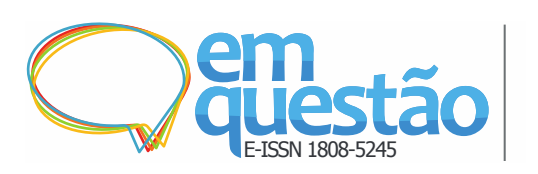

Diálogos entre as vertentes clássica, moderna e contemporânea da Arquivologia

Alex de Oliveira Costa e Cynthia Roncaglio

organogramas e regimentos. A análise é feita de baixo para cima, a partir da peça documental (bottom-up diplomatic analysis), do documento individual [...] (TOGNOLI, 2010, p. 90-91).

Diferente de Terry Cook, a análise proposta por Duranti faz o caminho inverso, ou seja, a partir do estudo da forma documental, que pode ser analisada independentemente do seu conteúdo, é possível identificar o contexto de produção dos documentos.

Duranti compreende o princípio da proveniência como fundamental para a Arquivologia, ressaltando que o respeito aos fundos e à ordem original são seus desdobramentos. O princípio ganha uma nova abordagem, focada no entendimento do contexto da produção documental. A autora “'[...] acredita na importância de se conhecer e estudar os produtores e as 'multiprocedências' dos arquivos [...]", reconstituindo, assim, funções, competências, atividades e unidades administrativas para efetuar a descrição e a análise diplomática (DURANTI, 1996, p. 82 13 apud KUROKI, 2016, p. 66).

Ao afirmar que os documentos arquivísticos representam um tipo de conhecimento único, Duranti (1994) os define como:

[...] produzidos ou recebidos no curso das atividades pessoais ou institucionais, como seus instrumentos e subprodutos, os documentos arquivísticos são as provas primordiais para as suposições ou conclusões relativas a essas atividades e às situações que elas contribuíram para criar, eliminar, manter ou modificar [...] (DURANTI, 1994, p. 50).

Nesse conceito, Duranti afirma que os documentos arquivísticos são instrumentos e subprodutos das atividades pessoais ou institucionais. Assim como Jenkinson (1922), a autora também estabelece o caráter probatório de uma ação como característica indispensável ao documento de arquivo.

Duranti (1994) identifica cinco características pertencentes ao documento arquivístico. A primeira é a imparcialidade. Para a autora, os documentos são inerentemente verdadeiros, as razões pelas quais eles são produzidos (para desenvolver atividades) e as circunstâncias de sua criação (rotinas processuais) asseguram que não são escritos "[...] na intenção ou para a informação da posteridade [...]" (DURANTI, 1994, p. 51-52). A segunda é a autenticidade, que está vinculada ao continuum da criação, manutenção e 


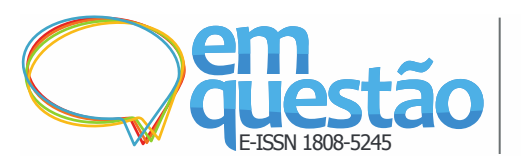

Diálogos entre as vertentes clássica, moderna e contemporânea da Arquivologia

Alex de Oliveira Costa e Cynthia Roncaglio

custódia. Por isso, os documentos arquivísticos só são autênticos quando são criados, mantidos e conservados sob custódia de acordo com procedimentos regulares que podem ser comprovados. A terceira é a naturalidade, que diz respeito à maneira como os documentos se acumulam no curso das transações. A autora identifica que os documentos não são "[...] coletados artificialmente, como os objetos de museu, mas são acumulados naturalmente em função dos objetivos práticos da administração [...]" (DURANTI, 1994, p. 51-52). A quarta é o inter-relacionamento, que é devido ao fato de que os documentos estabelecem relações no decorrer do andamento das transações e de acordo com suas necessidades. Cada documento está intimamente relacionado com outros e seu significado depende dessas relações. Por fim, a quinta característica é a unicidade. Duranti afirma que cada documento assume um lugar único na estrutura documental do grupo ao qual pertence e no universo documental (DURANTI, 1994).

Considerando a Diplomática como base para o conceito, Duranti, Eastwood e MacNeil (2002) identificam também três requisitos fundamentais para o documento arquivístico: estar escrito, ou afixado, em um suporte com uma sintaxe; estar relacionado a um fato que tem a ver com o sistema jurídico no qual é produzido; e ter uma forma, uma apresentação de acordo com regras preestabelecidas.

Outro aspecto essencial destacado por Duranti para considerar um documento como arquivístico é o conceito de vínculo arquivístico (archival bond), que afirma a natureza dos arquivos e os diferencia de outros materiais. Para Duranti (1997), o vínculo é definido como “[...] a rede de relacionamentos que cada documento arquivístico tem com os documentos que pertencem ao mesmo conjunto [...]” (DURANTI, 1997, p. 215-216, tradução nossa) ${ }^{14}$. No entender de Duranti (1997), o vínculo arquivístico surge no momento em que o documento é retido e unido a outro do decorrer da ação (DURANTI, 1997, p. 216).

Além disso, Duranti (1997) destaca que esse vínculo arquivístico não deve ser confundido com o contexto, o qual está fora do documento, enquanto 


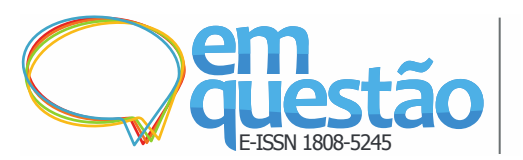

Diálogos entre as vertentes clássica, moderna e

contemporânea da Arquivologia

Alex de Oliveira Costa e Cynthia Roncaglio

que o vínculo arquivístico é parte essencial do documento arquivístico, o qual não pode existir sem esse vínculo (Duranti, 1997, p. 217).

\section{Considerações finais}

A transformação tecnológica contemporânea e o fato de o documento de arquivo passar a ser produzido em ambiente digital contribuíram significativamente para a ampliação do debate teórico e metodológico sobre os princípios e conceitos fundamentais da Arquivologia.

A produção atual dos documentos de arquivo ocorre principalmente em meio digital, e a tendência da substituição da produção dos documentos em ambientes convencionais para ambientes digitais é irreversível. Além disso, a revolução tecnológica em curso ainda sinaliza muitas mudanças que acontecerão com mais brevidade do que as mudanças tecnológicas vividas nos séculos anteriores. Isto significa que a Arquivologia continuará necessitando pensar e repensar seus instrumentais teóricos, metodológicos e práticos.

A Arquivologia não é fruto apenas de uma teoria ou uma evolução linear. Ela se constrói por meio de várias vertentes com ideias contraditórias, conflituosas ou até semelhantes. Geralmente, esses autores dão ênfase a determinados assuntos em detrimento de outros, devido às especificidades espaço-temporais de suas pesquisas, experiências profissionais e/ou interesses particulares.

As diferentes abordagens, muitas vezes, expressam as mesmas ideias, só que a partir de termos e conceitos diferentes. Por exemplo, a Arquivística Integrada, ao invés de utilizar o termo documento de arquivo, usa informação orgânica. Logo após, conceitua a informação orgânica como aquela que é elaborada, enviada ou recebida no âmbito da missão da organização. Percebemos que estão falando sobre o mesmo conceito de documento de arquivo, porém, utilizam termos diferentes, como se a expressão informação fosse mais atual do que documento.

Destacamos a ideia inovadora das abordagens pós-custodiais, ao mencionar a prevalência do contexto por trás do texto, no qual o contexto seria 


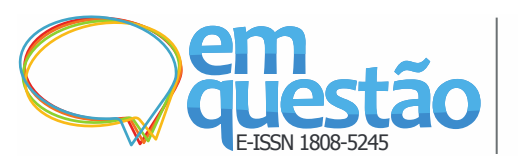

Diálogos entre as vertentes clássica, moderna e contemporânea da Arquivologia

Alex de Oliveira Costa e Cynthia Roncaglio

mais importante que o conteúdo do documento. Ao explorarmos as diferentes ideias de cada vertente, identificamos que todas parecem ter a mesma referência, só que expressas de maneira diferente. Jenkinson (1922) afirma que a verdade arquivística está relacionada ao contexto de criação; Casanova (1928) diz que a recuperação da informação envolve o contexto de criação; Brenneke (1968) declara que o princípio da proveniência é a representação intelectual do contexto de produção dos documentos e que, por meio da descrição, é possível representá-lo; Cook (1997) anuncia que o foco é o contexto por trás do texto; Thomassen (1999) alega que o novo objeto da Arquivologia, o process-bound information, possibilita a recuperação contextual; e Duranti (1996) proclama uma nova abordagem do princípio da proveniência baseada no contexto da produção documental. Ou seja, as abordagens possuem propósitos semelhantes, mas utilizam termos e métodos diferentes. Por exemplo, Duranti afirma que a partir do estudo da forma documental é possível identificar o contexto de produção, enquanto que Cook faz o caminho inverso e analisa no sentido do criador para o documento, buscando uma melhor compreensão da função e das atividades que o geraram.

Por fim, entendemos esses tipos de embates como algo próprio do campo científico e que os diálogos entre as vertentes clássica, moderna e contemporânea da Arquivologia são possíveis e passíveis, de maior rigor e análise crítica, na medida em que ideias e discursos forem confrontados, comparados e contextualizados.

\section{Referências}

ASSOCIAÇÃO DOS ARQUIVISTAS HOLANDESES. Manual de arranjo e descrição de arquivos. 2. ed. Rio de Janeiro: Arquivo Nacional, 1973.

BRENNEKE, A. Archivistica: contributo alla teoria ed alla storia archivistica europea. Milano: Per i tipi dell'editore, 1968.

CASANOVA, E. Archivistica. 2. ed. Siena: Stab. Arti Grafiche Lazzeri, 1928. 
COOK, T. Archival science and postmodernism: new formulations for old concepts. Archival Science, [s. l.], v. 1, n. 1, p. 3-24, 2000.

COOK, T. Electronic Records, Paper Minds: The Revolution in Information Management and Archives in the Post-Custodial and Post-Modernist Era. Archives \& Social Studies: A Journal of Interdisciplinary Research, Porto, v. 1, p. 399-443, 2007.

COOK, T. Macroappraisal in theory and practice: origins, characteristics, and implementation in Canada, 1950-2000. Archival Science, [s. l.], v. 5, p. 101$161,2005$.

COOK, T. What is past is prologue: a history of archival ideas since 1898, and the future paradigm shift. Archivaria, Ottawa, v. 43, p. 17-63, 1997.

DURANTI, L. Diplomatics. In: BATES, M. J.; MAACK, M. N. (eds.).

Encyclopedia of Library and Information Science. 3. ed. Boca Raton: CRC Press, 2009, p. 1-9.

DURANTI, L.; EASTWOOD, T.; MACNEIL, H. Preservation of the integrity of electronic records. Dordrecht: Kluwer Academic, 2002.

DURANTI, L. Registros documentais contemporâneos como prova de ação. Revista Estudos Históricos, Rio de Janeiro, v. 7, n. 13, p. 49-64, 1994.

DURANTI, L. The archival bond. Archives and Museum Informatics, [s. l.], v. 11, p. 213-218, 1997.

GIDDENS, A.; SUTTON, P. W. Conceitos essenciais da Sociologia. São Paulo: Editora Unesp, 2016.

JENKINSON, H. A manual of archive administration including the problems of war archives and archive making. Londres: Oxford, 1922.

KOSELLECK, R. Futuro passado: contribuição à semântica dos tempos históricos. Rio de Janeiro: Contraponto/Editora PUC-Rio, 2006.

KUHN, T. The Structure of Scientific Revolutions. 2. ed. Chicago: The University of Chicago, 1962. 
KUROKI, I. F. M. Demarcações conceituais dos princípios científicos da arquivologia e da ciência da informação: contribuições para a configuração científica das disciplinas no Campo da Informação. 2016. Dissertação (Mestrado em Ciência da Informação) - Faculdade de Ciência da Informação, Universidade de Brasília, Brasília, 2016.

MCKEMMISH, S. et al. (orgs.). Archives: recordkeeping in society. Wagga: Centre for Information Studies, 2005.

MERTON, R. Sociologia: teoria e estrutura. São Paulo: Editora Mestre Jou, 1970.

RIBEIRO, F. A arquivística como disciplina aplicada no campo da ciência da informação. Perspectivas em Gestão \& Conhecimento, João Pessoa, v. 1, n. 1, p. 59-73, jan./jun. 2011.

RONDINELLI, R. C. O documento arquivístico ante a realidade digital: uma revisitação conceitual necessária. Rio de Janeiro: Editora FGV, 2013.

ROUSSEAU, J.; COUTURE, C. Os fundamentos da disciplina arquivística. Lisboa: Publicações Dom Quixote, 1998.

SCHELLENBERG, T. R. Arquivos modernos: princípios e técnicas. Rio de Janeiro: FGV, 2005.

SCHELLENBERG, T. R. Modern Archives: Principles and Techniques.

Chicago: University of Chicago Press, 1956.

SCHMIDT, C. M. dos S. Arquivologia e a construção do seu objeto científico: concepções, trajetórias, contextualizações. 2012. Tese (Doutorado em Ciência da Informação) - Escola de Comunicações e Artes, Universidade de São Paulo, São Paulo, 2012.

SCOTT, P. J. The record group concept: a case for abandonment. The American Archivist, Chicago, v. 29, n. 4, p. 493-504, 1966.

THOMASSEN, T. The development of archival science and its European dimension. Archol: Archivistika On Line, Stockholm, 1999. Disponível em: 


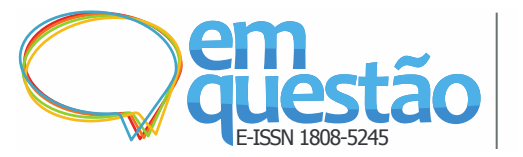

Diálogos entre as vertentes clássica, moderna e contemporânea da Arquivologia

Alex de Oliveira Costa e Cynthia Roncaglio

http://z-a-d.net/the-development-of-archival-science-and-its-europeandimension/. Acesso em: 18 abr. 2018.

\title{
TOGNOLI, N. B. A contribuição epistemológica canadense para a
} construção da arquivistica contemporânea. 2010. Dissertação (Mestrado em Ciência da Informação) - Faculdade de Filosofia e Ciências, Universidade Estadual Paulista "Júlio de Mesquita Filho", Marília, 2010.

TRIGUEIRO, M. G. S. Ciência, verdade e sociedade: contribuições para um diálogo entre Sociologia e a Filosofia da Ciência. Belo Horizonte: Fabrefactum, 2012

UPWARD, F. Structuring the Records Continuum - Part One: Postcustodial principles and properties. Archives and Manuscripts, [s. l.], v. 24, n. 2, p. 268285, 1996.

\section{The dialogue between the classic, modern and contemporary aspects of Archival Science}

\begin{abstract}
The principle of provenance and the concepts of record and organicity that guide Archival Science since the nineteenth century seem, at least partially, no longer sufficient to explain and guide the production of contemporary records. This article aims to analyze the arguments and assumptions of the classical, modern and contemporary aspects of Archival Science, which demonstrate the particularities and contributions of each one. The research is characterized as qualitative, exploratory, analytical and descriptive, in which the method adopted is the bibliographic survey. The theoretical framework was based on the history of the concepts of author Reinhart Koselleck and on the concepts of scientific ethos and discourse. It was observed in the clash between different ideas and different approaches, considered sometimes antagonistic, that a dialogue between them is possible through processes of re-signification of the principles and concepts throughout the own evolutionary dynamics of science.
\end{abstract}

Keywords: Archival Science. Record. Principle of Provenance. Organicity.

Recebido: 13/02/2019

Aceito: 16/07/2019 
${ }^{1}$ No original: "The fonds is the chief Archive Unit in the Continental system and the basis of all rules as to arrangement. The most important of all principles of Archive Management is named from it le respect pour les fonds."

${ }^{2}$ No original: "A document which may be said to belong to the class of Archives is one which was drawn up or used in the course of an administrative or executive transaction (whether public or private) of which itself formed a part; and subsequently preserved in their own custody for their own information by the person or persons responsible for that transaction and their legitimate successors."

${ }^{3}$ No original: "[...] la raccolta ordinata degli atti di um ente o individuo, costituitasi durante lo svolgimento dela sua attività e conservata per il conseguimento degli scopi politici, giuridici e culturali di quell'ente o individuo."

${ }^{4}$ No original: "[...] la totalità di scritti e di altri documenti, che si sono formati presso persone fisiche o giuridiche in base ala loro attività pratica o giuridica e che, quali fonti documentarie e prove del passato, sono destinati a permanente conservazione in um determinato luogo."

${ }^{5}$ MCKEMMISH, S.; UPWARD, F. The Archival Document: A submission to the Inquiry into Australia as an information Society. Archives and Manuscripts, 19, n. 1, 1991, p. 17-32. Apud Mckemmish et al. (2005).

${ }^{6}$ No original: “[...] the archival document can best be conceptualized as recorded information arising out of transactions - it is created naturally in the course of transacting business of any kind, whether by governments, businesses, community organizations or private individuals."

${ }^{7}$ No original: "[...] from the time the record is created and the archival document retains evidential value for as long as it is in existence [...]".

${ }^{8}$ No original: "In this fluid electronic environment, the idea of a record physically belonging in one place or even in one system is crumbling before new conceptual paradigms, where "creatorship" is a more fluid process of manipulating information from many sources in a myriad of ways, or applications, rather than something leading to a static, fixed, physical product."

${ }^{9}$ No original: "[...] A record thus changes from being a physical object to becoming a conceptual data "object", controlled by metadata, that virtually combines content, context, and structure to provide evidence of some creator activity or function. Moreover, as a record's context and uses change over time (including archival uses), the metadata changes, and the record and its context is continually being renewed. Records are no longer fixed, but dynamic."

${ }^{10}$ No original: "[...] macroappraisal assesses the societal value of both the functional-structural context and work-place culture in which the records are created and used by their creator(s), and the interrelationship of citizens, groups, organizations - "the public" - with that functional-structural context. If appraisal designates the long-term value of the content of records, or series of records, for their potential research values, macroappraisal assesses the significance of the context of their creation and contemporary use. Appraisal is about records; macroappraisal is about their broader (or "macro") context."

${ }^{11}$ No original: "[...] we archivists, [...] are literally co-creating archives. We are making history. We are exercising power over memory."

${ }^{12}$ No original: "[...] has adapted, elaborated, and developed the core concepts and methodology of classic diplomatics in order to study modern and contemporary records of all types."

${ }^{13}$ DURANTI, Luciana. Diplomática: usos nuevos para uma antigua ciência. Carmona (Sevilla): S \& C ediciones, 1996. Apud Kuroki (2016).

${ }^{14}$ No original: "[...] the network of relationships that each record has with the records belonging in the same aggregation." 